\title{
Role of the Dorsomedial Striatum in Behavioral Flexibility for Response and Visual Cue Discrimination Learning
}

\author{
Michael E. Ragozzino and Katharine E. Ragozzino \\ University of Illinois at Chicago
}

\author{
Sheri J. Y. Mizumori \\ University of Washington
}

\author{
Raymond P. Kesner \\ University of Utah
}

\begin{abstract}
These experiments examined the effects of dorsomedial striatal inactivation on the acquisition of a response and visual cue discrimination task, as well as a shift from a response to a visual cue discrimination, and vice versa. In Experiment 1, rats were tested on the response discrimination task followed by the visual cue discrimination task. In Experiment 2, the testing order was reversed. Infusions of $2 \%$ tetracaine did not impair acquisition of the response or visual cue discrimination but impaired performance when shifting from a response to a visual cue discrimination, and vice versa. Analysis of the errors revealed that the deficit was not due to perseveration of the previously learned strategy, but to an inability to maintain the new strategy. These results contrast with findings indicating that prelimbic inactivation impairs behavioral flexibility due to perseveration of a previously learned strategy. Thus, specific circuits in the prefrontal cortex and striatum may interact to enable behavioral flexibility, but each region may contribute to distinct processes that facilitate strategy switching.
\end{abstract}

There have been several different theories regarding the function of the striatum in learning and memory over the past several decades (Devan \& White, 1999; Devan, McDonald, \& White, 1999; Kesner, 1998; Kesner, Bolland, \& Dakis, 1993; Knowlton, Mangels, \& Squire, 1996; McDonald \& White, 1993; Packard, Hirsh, \& White, 1989). Kesner (1998) and Potegal (1969) have argued that the striatum plays a critical role in memory for egocentric responses, a type of memory based on proprioceptive and vestibular feedback (Adams, Kesner, \& Ragozzino, 2001; Cook \& Kesner, 1988; Duncan-Davis, Filoteo \& Kesner, 1996; Ghiselli \& Brown, 1938; Kesner, 1998; Kesner et al., 1993; Potegal, 1969). In support of this idea, findings from some studies indicate that striatal lesions in rats impair short-term memory for a particular motor response, that is, remembering whether a left or right turn was just made, as well as retention of a learned response pattern (e.g., always makes a turn in a proximal maze arm; Colombo,

Michael E. Ragozzino and Katharine E. Ragozzino, Department of Psychology, University of Illinois at Chicago; Sheri J. Y. Mizumori, Department of Psychology, University of Washington; Raymond P. Kesner, Department of Psychology, University of Utah.

This research was supported by National Institute of Mental Health (NIMH) Grant MH 61889 to Michael E. Ragozzino, National Institutes of Health Grant NS20771 to Raymond P. Kesner, and NIMH Grant MH 58755 and National Science Foundation Grant IBN 9514880 to Sheri J. Y. Mizumori. Katharine E. Ragozzino was the recipient of National Science Foundation Fellowship DGE 9616182.

Correspondence concerning this article should be addressed to Michael E. Ragozzino, Department of Psychology, University of Illinois at Chicago, 1007 West Harrison Street, Chicago, Illinois 60607. E-mail: mrago@uic.edu
Davis, \& Volpe, 1989; Cook \& Kesner, 1988, Kesner et al., 1993; Potegal, 1969). The results from other investigations suggest that the deficit arises not from an inability to remember a particular response, but rather an impairment in forming the appropriate stimulus-response association (Aosaki, Kimura, \& Graybiel, 1995; Colombo et al., 1989; McDonald \& White, 1993, 1994; Mishkin, Malamut \& Bachevalier, 1984; Packard, 1999; Packard et al., 1989; Packard \& McGaugh, 1996; Winocur \& Eskes, 1998). More specifically, lesions or pharmacological manipulations of the striatum impair learning of the visual cue version of the Morris water maze and a visual-cue discrimination in a radial-arm maze in which rats must only enter arms that contain lights at the entrance (McDonald \& White, 1993, 1994; Packard \& Teather, 1997).

Other experiments have demonstrated that different striatal subregions contribute to different types of mnemonic and cognitivebehavioral processes (Devan \& White, 1999; Devan et al., 1999; Livesey \& Muter, 1976; Pisa \& Cyr, 1990; Winocur, 1974). These results are consistent with anatomical findings indicating that striatal subregions have different connectivity with other cortical and subcortical areas (Groenewegen \& Berendse, 1994; McGeorge \& Faull, 1989). Behavioral results indicate that lesions of the lateral striatum, but not the medial striatum, impair learning of motor skills or arbitrary stimulus-response associations (Devan \& White, 1999; Devan et al., 1999; Dunnett \& Iversen, 1982; Fricker, Annett, Torres, \& Dunnett, 1996; McDonald \& White, 1994; Pisa \& Cyr, 1990; Reading, Dunnett, \& Robbins, 1991). Conversely, lesions of the medial striatum have produced deficits on spatial learning and reversal learning but lateral striatal lesions have not impaired performance on these tasks (Devan \& White, 1999; Kolb, 1977; Pisa \& Cyr, 1990; Whishaw, Mittleman, Bunch, \& Dunnett, 1987). 
The findings that medial striatal lesions impair performance on reversal learning tasks suggest that this striatal region is important for the flexible shifting of strategies or response patterns under changing environmental conditions. In support of this view, patients with Parkinson's or Huntington's disease, two conditions that affect the striatum, routinely manifest cognitive flexibility deficits as shown by impairments on the Wisconsin Card Sorting Test or attentional-set shifting tests (Lawrence et al., 1996; Owen et al., 1993). Furthermore, recording of location and head-direction neurons from the rat dorsomedial striatum during a spatial working memory task indicates that the behaviorally correlated firing of these neurons is altered when environmental conditions change, demanding a flexible use of allocentric and egocentric information (Mizumori, Ragozzino, \& Cooper, 2000). Taken together, the results suggest that the striatum, and in particular the rat medial striatum, may play a critical role in behavioral flexibility.

Recent findings from our laboratory indicate that either inactivations or pharmacological manipulations of the prelimbic and infralimbic areas of the prefrontal cortex impair behavioral flexibility (Ragozzino, Detrick \& Kesner, 1999a, 1999b; Ragozzino, Wilcox, Raso, \& Kesner, 1999). Specifically, prelimbicinfralimbic inactivations do not impair acquisition or an intradimensional shift (reversal learning) of place and response discriminations (Ragozzino et al., 1999a, 1999b). However, inactivation of the prelimbic-infralimbic areas selectively impairs extradimensional shifts, when conditions demand inhibiting a strategy based on the use of one type of attribute information (i.e., place) and learning a new strategy based on different attribute information (i.e., visual cue; Ragozzino et al., 1999a, 1999b). Moreover, the behavioral flexibility deficits observed following prelimbic-infralimbic inactivations are due to perseveration of the previously learned strategy (Ragozzino et al., 1999a).

The projections of the prelimbic and infralimbic prefrontal subregions to the medial striatum form a portion of one of the cortical-basal ganglia-thalamic loops (Groenewegen \& Berendse, 1994, Uylings \& van Eden, 1990). This anatomical organization raises the possibility that the medial striatum may also be functionally related to the prelimbic and infralimbic areas (Groenewegen \& Berendse, 1994, Kolb, 1977). Previous experiments that examined the role of the striatum in behavioral flexibility have found that large striatal lesions impair intradimensional shifts (Divac, 1971; Hannon \& Bader, 1974; Kirkby, 1969; Kolb, 1977; Pisa \& Cyr, 1990; Schwartzbaum \& Donovick, 1968). Because prelimbic-infralimbic inactivation produced selective deficits on tests involving extradimensional shifts, the goal of the present experiments was to study the effects of dorsomedial striatal inactivation on behavioral flexibility tests that involve extradimensional tests. Although the prelimbic and infralimbic areas project to the medial striatum along most of the dorsal-ventral plane (Groenewegen \& Berendse, 1994), the microinfusions in the present experiments were targeted at the dorsomedial striatal region because previous studies have suggested that this area may be important for behavioral flexibility (Pisa \& Cyr, 1990). In these studies, shifts between response and visual cue discriminations were chosen because investigations in the past demonstrated that the striatum may be important for learning and memory of visual cue and response information (Cook \& Kesner, 1988; Devan \& White, 1999; Devan et al., 1999; Kesner et al., 1993; McDonald \&
White, 1993, 1994; Packard, 1999; Packard \& Teather, 1997; Pisa \& Cyr, 1990; Whishaw et al., 1987).

\section{Experiment 1: Effects of Dorsomedial Striatal Inactivation on Switching From Response Learning to Visual Cue Learning}

To determine whether the dorsomedial striatum is important for initial learning of a two-choice discrimination and/or behavioral flexibility involving extradimensional shifts, Experiment 1 examined whether tetracaine infusions into the dorsomedial striatum impairs acquisition of a response discrimination, a shift to a visual cue discrimination, or both.

\section{Method}

Subjects. Male Long-Evans rats (Charles River Laboratories, Indianapolis, IN) weighing between 325 and $375 \mathrm{~g}$ at the beginning of the experiment served as subjects. Rats were housed individually in stainless steel cages $(20 \mathrm{~cm}$ wide $\times 24 \mathrm{~cm}$ long $\times 20 \mathrm{~cm}$ high) located in a temperature controlled room $\left(24{ }^{\circ} \mathrm{C}\right)$ that was maintained at $20 \%-40 \%$ humidity. The rats were kept on a 12-hr light-dark cycle (lights on at 7 a.m.). All rats were food restricted to maintain their weight at approximately $85 \%$ of their ad libitum weight but had free access to water throughout the experiment.

Apparatus. The cross-maze was a four-arm maze made of $0.7-\mathrm{cm}-$ thick wood that was painted black. The maze was placed on a circular platform that was elevated $26 \mathrm{~cm}$ above the floor. Each arm was $50.8 \mathrm{~cm}$ long $\times 8.9 \mathrm{~cm}$ wide and the height of the arm wall was $16.5 \mathrm{~cm}$. Each arm contained a food well $(3.0 \mathrm{~cm}$ diameter $\times 2.5 \mathrm{~cm}$ high $)$ that was $3.2 \mathrm{~cm}$ from the end wall. Each food well hole was $2.0 \mathrm{~cm}$ in diameter and 1.25 $\mathrm{cm}$ deep. The center platform was $18 \times 18 \mathrm{~cm}$.

Surgery. Rats received atropine sulfate $(0.2 \mathrm{ml}$ of a $250 \mu \mathrm{g} / \mathrm{ml}$ solution ip) $20 \mathrm{~min}$ before administering the general anesthetic (sodium pentobarbital, $50 \mathrm{mg} / \mathrm{kg}$ ip). A midsagittal incision was made, and the scalp was retracted. Each rat received a bilateral implant of an 8-mm stainless steel guide cannula (22 gauge, Plastics One, Roanoke, VA) aimed toward the dorsomedial striatum. The stereotaxic coordinates were $1.2 \mathrm{~mm}$ anterior to bregma, $\pm 2.0 \mathrm{~mm}$ lateral to the midline, and $3.5 \mathrm{~mm}$ ventral to dura. The incisor bar was lowered to $3.3 \pm 0.2$ below horizontal zero so that the height of bregma and lambda were equal. The coordinates were based on the atlas of Paxinos and Watson (1996). Four jeweler's screws were placed in the skull surrounding the cannulas. The cannulas were secured in place with dental acrylic (Plastics One). Stylets were secured in the guide cannulas after the dental acrylic dried. After surgery, rats received ground rat chow (PMI Nutrition International, Brentwood, MO) mixed in water for 2 days.

Microinfusion. Injections into the dorsomedial striatum were made through an inner cannula (28 gauge) that extended $1.0 \mathrm{~mm}$ below the guide cannula. The inner cannula was attached by a polyethylene tube (PE-20) to a 10- $\mu$ l Hamilton syringe. The syringe was driven by a microinfusion pump (74900 Series, Cole-Parmer, Vernon Hills, IL) with solutions infused in a volume of $0.5 \mu \mathrm{l}$ per side for $2 \mathrm{~min}$. This is the same volume used in previous studies involving microinfusions into the striatum (Beninger \& Ranaldi, 1993; Haralambous \& Westbrook, 1999; Packard, 1999; Packard \& White, 1991; White \& Viaud, 1991). This volume was also used to limit the spread to the targeted dorsomedial striatal area, which was expected to be sufficient on the basis of the spread of the microinfusion using the same volume in previous experiments (Ragozzino et al., 1999a; Ragozzino \& Kesner, 1998). The inner cannula was left in place for $1 \mathrm{~min}$ after completion of the infusion to allow for diffusion. Rats received either $2 \%$ (wt/vol) tetracaine hydrochloride (Sigma, St. Louis, MO) or saline. Tetracaine hydrochloride was mixed in saline. Tetracaine acts as a local anes- 
thetic that acts principally by blocking sodium channels (Velly, Grima, Decker, Cragoe, \& Schwartz, 1988; Thomsen, Hays, Hicks, Schwartz, \& Catteral, 1993). A $2 \%$ tetracaine solution was used on the basis of previous behavioral and electrophysiological experiments using this concentration in which intracranial injections were found to alter neuronal activity for 15-20 min (Mizumori, McNaughton, Barnes, \& Fox, 1989; Mizumori, Perez, Alvarado, Barnes, \& McNaughton, 1990; Ragozzino et al., 1999a, 1999b).

Habituation procedure. Rats were allowed 7-10 days to recover from surgery before the habituation procedure commenced. Two days after surgery rats were food restricted to $85 \%$ of their original ad libitum weight. During food restriction, rats were also handled for $10 \mathrm{~min}$ per day. On the 1st day of habituation, three pieces of Froot Loops cereal (Kelloggs, Battle Creek, MI) were placed in each arm, with two pieces in the food well and one piece outside the food well. A rat was placed in the maze and allowed to freely navigate and consume cereal pieces for $15 \mathrm{~min}$. If a rat consumed all 12 cereal pieces before the 15 min was completed, then the rat was placed in a holding cage and the maze was rebaited. On the 2 nd habituation day, the procedure was similar except that after a rat consumed two cereal pieces, the rat was picked up and placed in a different arm. This acclimated the rat to being handled in the maze after consuming cereal. On the 3rd habituation day, the procedure was the same as on Day 2, except that there were only two cereal pieces put in each food well for a total of eight cereal pieces. Furthermore, a white piece of posterboard $(8 \mathrm{~cm}$ wide $\times 48 \mathrm{~cm}$ long $\times 0.3 \mathrm{~cm}$ thick) was placed in one of the arms. After a rat consumed all eight pieces and was placed in the holding cage, the visual cue was moved to a different arm and the food wells were rebaited. Immediately after consuming the cereal on Day 3, the turn bias for a rat was determined. For assessing the turn bias, the maze was made into a $\mathrm{T}$ maze by placing a wood block ( $9 \mathrm{~cm}$ wide $\times 13 \mathrm{~cm}$ high $\times 1.25 \mathrm{~cm}$ thick, painted black) such that it prevented entry into one arm. No cereal was placed in the food wells during this procedure. The rat was placed in the "stem" arm and could turn $90^{\circ}$ left or right after reaching the middle area. After making a turn and reaching the end of an arm, the rat was placed back in the holding cage. Before the beginning of the next trial, the maze was wiped with a sponge moistened with a $1 \%$ didecyl dimethyl ammonium chloride solution. Each rat received a maximum of seven trials. A rat's turn bias was determined when it made four turns in one direction. A rat was required to turn in the opposite direction as its turn bias during testing in the response discrimination.

After determining the turn bias, a rat's stylets were removed from the guide cannulas and an injection cannula was inserted for $1 \mathrm{~min}$. There was no solution injected at this time. This procedure was performed to prevent clogging of the microinfusion on test days. Behavioral testing was started the next day.

Response-visual cue testing procedure. The testing procedure was modified from that of Ragozzino et al. (1999a). For each discrimination, three start arms were used. In this experiment, each rat was started on the response version. A rat was started from the arms designated $\mathrm{W}, \mathrm{S}$, and $\mathrm{E}$ (see Figure 1). A rat always had a choice to make a $90^{\circ}$ turn to the left or to the right. The visual cue was placed pseudorandomly in one of the choice arms such that it occurred an equal number of times in each choice arm. At each start arm, a rat had to make the same turn to receive a half piece of Froot Loops cereal. There were 24 trials per daily session, with each start arm used an equal amount but presented in a random fashion. Between trials, the rat was placed back in the holding cage, which sat on a shelf next to the maze. Subsequently, the maze arms were wiped down with a sponge moistened with the ammonium chloride solution. The

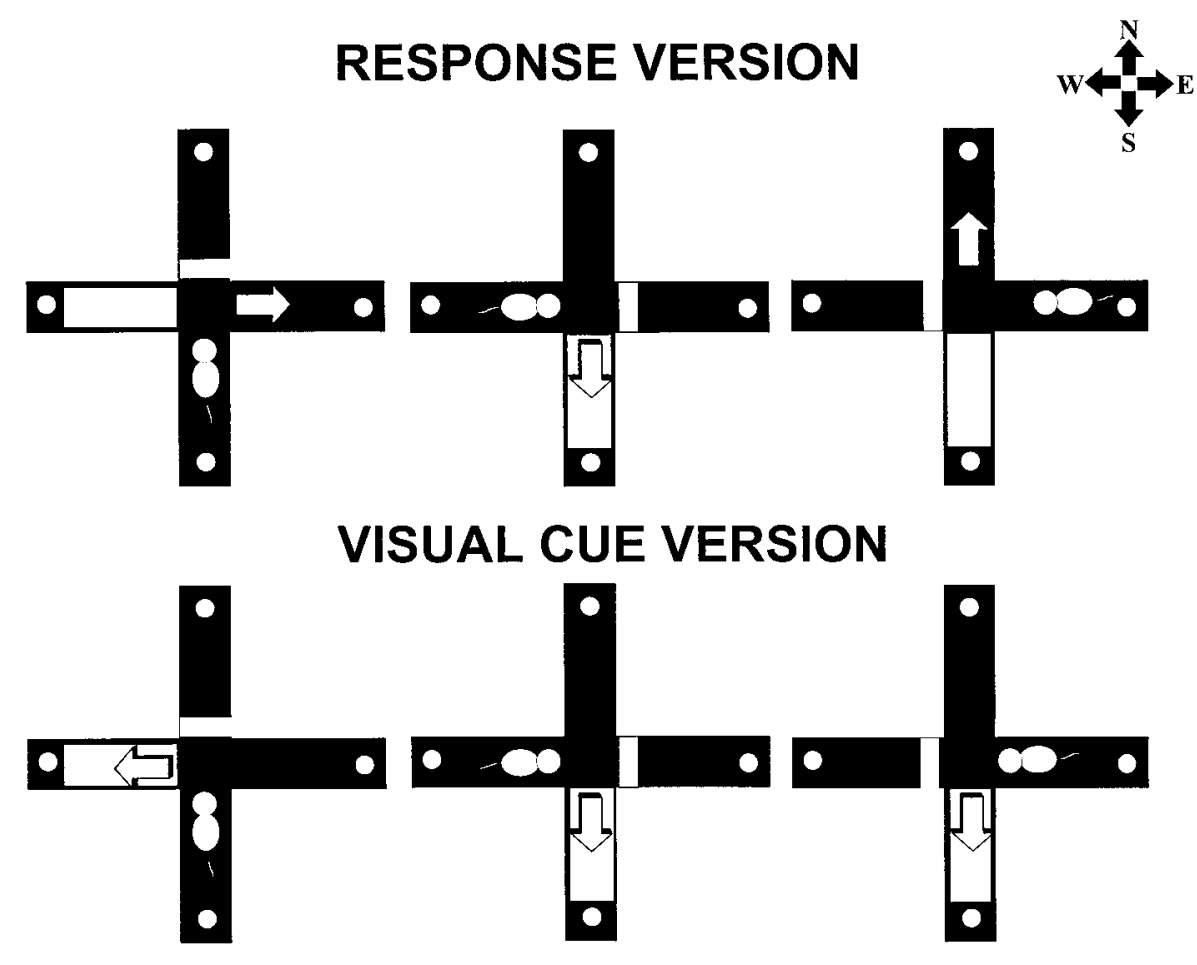

Figure 1. Example of a rat tested on the response and visual cue discrimination tasks. In each task, a rat had a choice to turn to the left or to the right. A white visual cue was randomly placed in one of the choice arms on each trial. In the response version, this rat was started from the South, West, and East arms and always had to make a $90^{\circ}$ turn to the right to receive a cereal reinforcement. In the visual cue version, the rat was started from the same arms but always had to enter the visual cue arm that did not depend on always making the same type of turn. The arrows in the maze represent the correct navigation pattern to receive a reinforcement. 
intertrial interval was approximately $10 \mathrm{~s}$. To minimize the use of intramaze cues from the apparatus, every four trials the maze was turned $90^{\circ}$ clockwise relative to the experimenter. Once a rat made 10 correct choices consecutively, a probe trial was given. The probe trial consisted of starting the rat from the fourth arm $(\mathrm{N})$ that was not used during testing. If a rat correctly turned the same direction as on testing, then the response procedure was completed. If a rat made an incorrect turn, then response testing was continued until a rat made an additional five correct choices consecutively, at which time another probe trial was administered. This procedure was continued until a rat made a correct choice on the probe trial. In situations in which a rat missed a probe trial and less than 5 test trials were left in the 24-trial session, the rat was still tested for the few remaining trials. However, any correct choices at the end of a session did not carry over to the next session. The following measures were taken for each rat: (a) acquisition criterion, defined as the total number of test trials to complete 10 consecutive correct choices in a session; (b) trials to criterion, defined as the total number of test trials completed before a correct choice on the probe trial was made; and (c) probe trials, defined as the total number of probe trials to get one correct. On the basis of these criteria, it was possible that the scores for the acquisition criterion and trials to criterion were the same if a rat made a correct choice on the first probe trial.

The day after reaching criterion on the response version, rats were switched to the visual cue version. In the visual cue version, a similar procedure was used as in the response version. However, in this test the rat always had to enter the arm with the visual cue. The visual cue was located in the left and right arms an equal amount per session. Figure 1, bottom, shows an example of a rat that learned to always enter the visual cue arm. The same start arms, number of trials per session, and criteria to complete the visual cue version were used as described in the response version. Additional measures were analyzed on the switch to determine whether treatments altered perseveration or reversions back to the previously correct response pattern after perseveration had ceased. Perseveration involved continuing to make the same egocentric response, as required on the response version, when the trial required turning the opposite direction to enter the visual cue arm. There were 12 of these trials per session, which were separated into three blocks of 4 trials each. Perseveration was defined as entering the incorrect arm in three or more trials per block. This is a similar criterion as used in previous experiments measuring perseveration (Hunt \& Aggleton, 1998; Ragozzino et al., 1999a). Once a rat made less than three errors in a block the first time, all subsequent errors were no longer counted as perseverative errors. When perseveration ended, as defined above, the number of errors was counted when a rat reverted back to the previously correct response on those trials that required the opposite turn as on the response version. These errors are referred to as regressive errors. Errors on these trials were counted as regressive errors including when a rat made the incorrect choice three or more times in a block after perseveration stopped. During the switch, a third type of error could be made if a rat turned in the opposite direction on the 12 trials in which the turn in the visual cue arm was the same egocentric response required on the acquisition phase. These errors were also calculated for each rat.

Three minutes before each test session, rats received a microinfusion. Each rat was randomly assigned to one of the three treatment groups. Group assignment was determined by which treatment was administered during each version: (a) response version-saline and visual cue versionsaline $(n=6)$; (b) response version-saline and visual cue version-2\% tetracaine $(n=6)$; and (c) response version-2\% tetracaine and visual cue version-saline $(n=6)$. Group 1 served as the control group. Group 2 determined whether dorsomedial striatal inactivation impaired behavioral flexibility when switched to a different discrimination version. Group 3 determined whether dorsomedial striatal inactivation impaired acquisition of response discrimination learning. Saline infusions were administered to Group 3 on the switch to determine whether multiple tetracaine infusions on acquisition may have produced neuronal damage that led to behavioral impairments but were not manifested until rats were switched to a different discrimination.

Histology. After completion of behavioral testing, rats received a lethal dose of sodium pentobarbital followed by a $0.5-\mu$ l injection of $2.5 \%$ Chicago blue stain through each guide cannula. As in previous experiments (Ragozzino et al., 1999a, 1999b), the stain was used to highlight the approximate spread of the intracranial injections. Rats were perfused intracardially with $0.9 \%(\mathrm{wt} / \mathrm{vol})$ saline followed by a $4 \%(\mathrm{wt} / \mathrm{vol})$ formaldehyde solution. Brains were removed and stored in a $30 \%$ sucroseformalin solution. The brains were frozen and cut in coronal sections (40 $\mu \mathrm{m})$ on a cryostat. The sections were mounted on slides, dried, and examined to determine the location of the cannula tips and the spread of the stain. Subsequently, the brain sections were stained with cresyl violet to examine whether there were any gross structural changes in the brains after tetracaine infusions compared with those after vehicle infusions.

Statistical analysis. In both experiments, there was no difference between acquisition criterion and trials to criterion. Because of this, only the analysis on the trials to criterion is presented. However, analysis on the number of probe trials is presented. A separate analysis of variance (ANOVA) was done on the acquisition version and the switch version for both experiments. ANOVA tests were used to assess differences in perseveration and regressive errors among the groups.

\section{Results}

Histology. Figure 2 illustrates the location of the cannula tips in the dorsal striatum for Experiments 1 and 2. The analysis revealed that the injection tips were located in the anteriorposterior plane at the genu of the corpus callosum. In the mediallateral plane, injection tips were concentrated in the medial and central regions of the dorsal striatum. The dye injections indicated that fluid spread ventrolaterally from the injection site and was concentrated in the dorsal striatum. In all cases, the dye injections spread into the most dorsomedial regions of the striatum, which receive projections from the prelimbic and infralimbic areas (Groenewegen \& Berendse, 1994). In those cases where the cannula placement was more lateral, dye spread laterally into the more dorsal, central region of the striatum, which receives projections from the dorsal anterior cingulate area (Groenewegen \& Berendse, 1994), in addition to encompassing the dorsomedial striatal area. In the dorsal-ventral plane, the dye infusions indicated that the most ventral striatal placements had dye diffuse at the level of the lateral septum. In no cases did the dye spread into the nucleus accumbens region. In Experiment 1, a total of 4 rats were excluded from the behavioral analyses because of misplacements. All of these rats had cannula placements in which at least one side had dye in the ventricles.

Investigation of the Nissl-stained sections under a light microscope did not reveal any structural differences in the striatal sections from rats that received tetracaine infusions compared with those that only received vehicle infusions.

Response acquisition. The findings on the trials to criterion for response discrimination acquisition are shown in Figure 3A. The three groups took approximately 70-80 trials to reach criterion. The analysis indicated that there was not a significant difference among the groups for initial learning of the response discrimination, $F(2,15)=0.29, p>.05$. On acquisition, the mean number of probe trials $( \pm S E M)$ for the three groups was as follows: saline-saline $=1.33 \pm 0.21$; saline-tetracaine $=1.0 \pm 0.0$; tetracaine-saline $=2.0 \pm 0.82$. The difference in probe trials among the groups was not significant, $F(2,15)=1.09, p>.05$. 


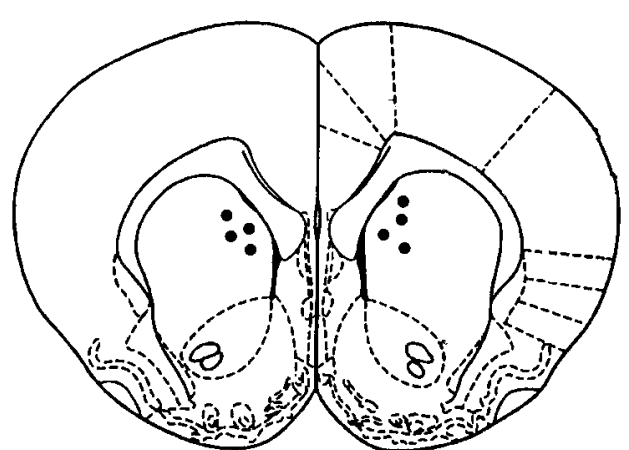

$+1.7$

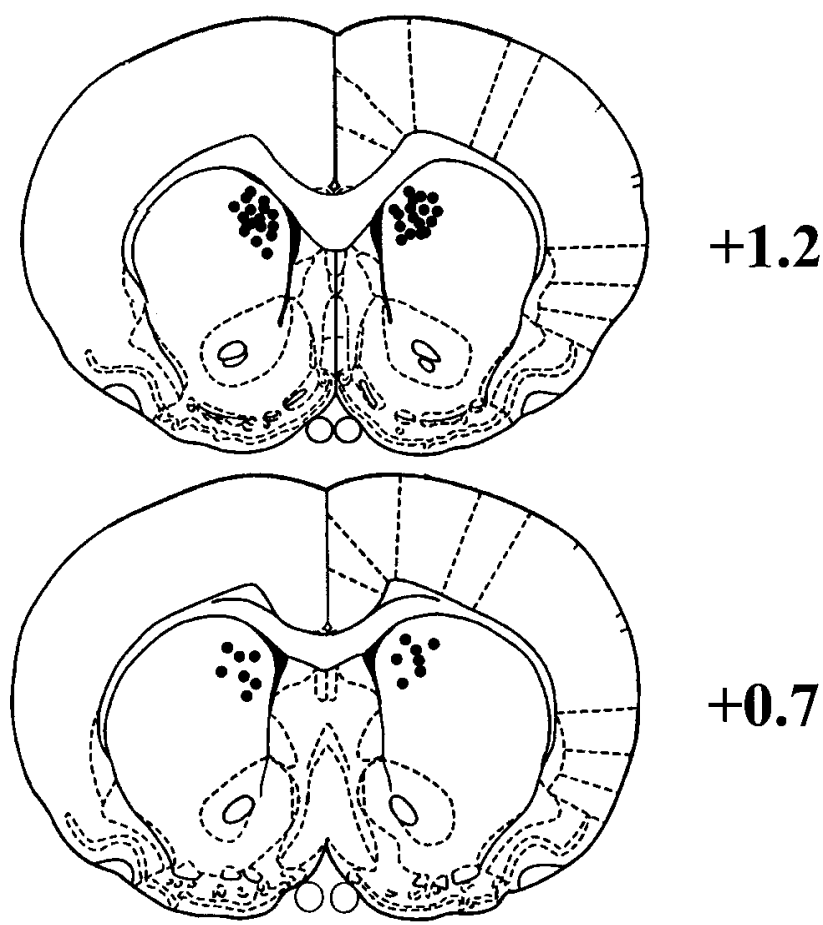

Figure 2. Placement of the cannula tips in the dorsomedial striatum for rats included in the behavioral analyses in Experiments 1 and 2. Cannula tips were concentrated in the dorsomedial striatal region, ranging from 0.7 to 1.7 anterior to bregma. The number of circles does not match the total number of rats included in the behavioral analyses because certain cannula placements were overlapping to such a large extent that a single circle represents more than one cannula placement. From The Rat Brain in Stereotaxic Coordinates (3rd ed., Figures 11, 13, and 15), by G. Paxinos and C. Watson, 1996, Sydney, Australia: Academic Press. Copyright 1996 by Academic Press. Adapted with permission.

Shift to visual cue. Figure 3B illustrates the results on the trials to criterion for the shift to visual cue discrimination learning. The two saline groups reached criterion in approximately 65-70 trials. In contrast, the tetracaine group was slower in reaching criterion, taking greater than 95 trials. The difference in trials to criterion among the groups was significant, $F(2,15)=8.09, p<.01$. A post hoc analysis with Newman-Keuls tests revealed that tetracaine infusions significantly increased the trials to criterion compared to those of the saline-treated groups $(p s<.01)$. However, the difference in trials to criterion between the saline groups was not significant $(p>.05)$. The following scores indicate the mean number $( \pm S E M)$ of probe trials to reach criterion for the three groups: saline-saline $=1.0 \pm 0.0$; saline-tetracaine $=1.0 \pm 0.0$; tetracaine-saline $=1.5 \pm 0.22$. The difference in the number of probe trials to reach criterion among the groups was significant, $F(2,15)=5.00, p<.05$. The significant difference is related to the tetracaine-saline group taking a greater number of probe trials than the other groups. The reason for the significant difference in probe trials between the groups is unclear, but does not alter the importance of the findings on the shift to the visual cue because both groups that received saline during this test session took a
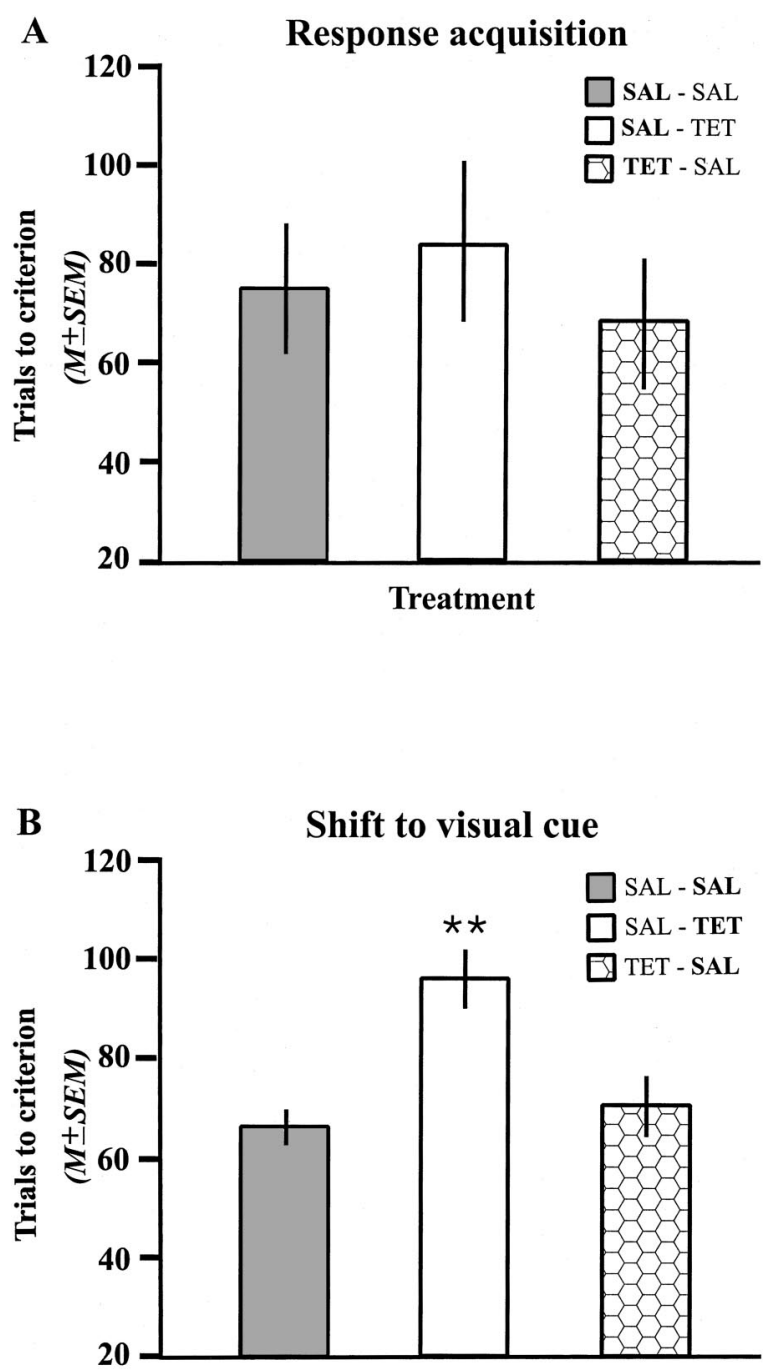

Treatment

Figure 3. A: Mean $( \pm S E M)$ trials to criterion on acquisition of the response discrimination after bilateral infusions of saline (SAL) or $2 \%$ $(\mathrm{wt} / \mathrm{vol})$ tetracaine (TET) into the dorsomedial striatum. TET infusions did not impair acquisition compared with SAL infusions. The treatment received on this test is shown in bold for each group. B: Mean ( \pm SEM) trials to criterion on the shift to the visual cue discrimination after SAL or TET infusions into the dorsomedial striatum. TET infusions significantly increased the trials to criterion compared with SAL infusions. The treatment received on this test is shown in bold for each group. Asterisks indicate a significant difference between treatment groups $(p<.01)$. 
comparable amount of trials to reach criterion (saline-saline $=66.5 \pm 3.5$; tetracaine-saline $=68.5 \pm 6.6$ ).

A further analysis of the trials to criterion on the shift to the visual cue discrimination revealed that dorsal striatum inactivation did not impair learning on the switch due to perseveration (see Figure 4A). The difference in perseverative errors among the groups was not significant, $F(2,15)=0.07, p>.05$. In contrast, there was a significant difference in regressive errors among the groups, $F(2,15)=4.25, p<.05$ (see Figure 4B). Newman-Keuls tests indicated that tetracaine-treated rats made significantly more
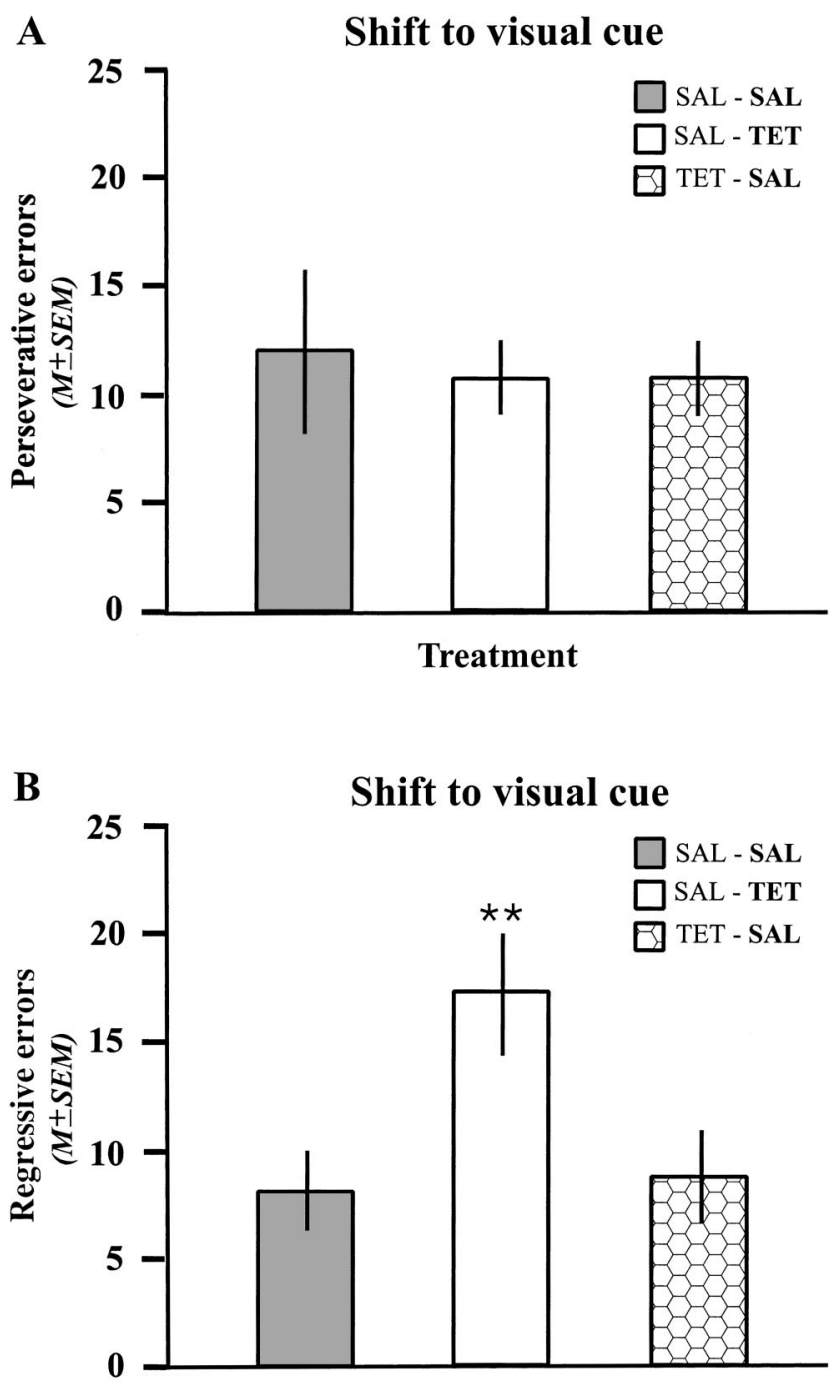

Treatment

Figure 4. A: Mean ( $\pm S E M)$ number of perseverative errors on the shift to the visual cue discrimination after saline (SAL) or $2 \%(\mathrm{wt} / \mathrm{vol})$ tetracaine (TET) infusions. TET infusions did not increase the number of perseverative errors compared with SAL infusions. The treatment received on this test is shown in bold for each group. B: Mean ( \pm SEM) number of regressive errors on the shift to the visual cue discrimination after SAL or TET infusions. TET infusions significantly increased regressive errors compared with SAL infusions. The treatment received on this test is shown in bold for each group. Asterisks indicate a significant difference between treatment groups $(p<.01)$. regressive errors than either of the saline-treated groups $(p \mathrm{~s}<$ $.05)$. The difference in regressive errors between the saline-treated groups was not significant $(p>.05)$.

Another possible error a rat could make on the reversal learning phase was on the trials in which the turn required to enter the visual cue arm was the same as the egocentric response required during acquisition. As observed in previous experiments, the majority of rats never made such an error. For this type of error, the mean scores were as follows for the groups: saline-saline $=0.5 \pm 0.34$, saline-tetracaine $=1.0 \pm 0.63$, and tetracainesaline $=0.5 \pm 0.34$. The difference in the errors among the groups was not significant, $F(2,15)=0.40, p>.05$.

\section{Experiment 2: Effects of Dorsomedial Striatal Inactivation on Switching From Visual Cue Learning to Response Learning}

The findings from Experiment 1 indicate that dorsomedial striatal inactivation does not impair response discrimination learning, but does impair a shift to visual cue discrimination learning. Unknown is whether the deficit is due to switching to a different type of learning or whether dorsomedial striatal inactivation specifically impairs learning a visual cue discrimination. To address this issue, Experiment 2 examined the effects of dorsomedial striatal inactivation on acquisition of a visual cue discrimination and on a shift to a response discrimination.

\section{Method}

Subjects. Male Long-Evans rats (Charles River Laboratories, Indianapolis, IN) weighing between 325 and $375 \mathrm{~g}$ at the beginning of the experiment served as subjects. The rats were maintained as described in Experiment 1.

Apparatus, surgery, microinfusion, habituation, histology, and statistical analysis. The same apparatus, statistical analysis, surgery, microinfusion, habituation, and histological procedures were used as described in Experiment 1.

Visual cue-response testing procedure. In this experiment, rats were started on the visual cue version, followed by testing on the response version. All other aspects of the testing procedure were as described in Experiment 1. On the switch to the response version, the same measures were assessed as those during the switch in Experiment 1. In this case, perseveration and regressive errors were analyzed from the 12 trials in which a rat was required to turn in the arm opposite to that of the visual cue. Each rat was randomly assigned to one of the following groups: (a) visual cue version-saline and response version-saline $(n=6)$, (b) visual cue version-saline and response version-2\% tetracaine $(n=7)$, and (c) visual cue version-2\% tetracaine and response version-saline $(n=7)$.

\section{Results}

Histology. Figure 1 shows the location of the cannula tips in the dorsomedial striatum. The findings were comparable as described in the Results section for Experiment 1.

One rat was excluded from the behavioral analyses because a cannula was located dorsal in the corpus callosum.

Visual cue acquisition. The findings on acquisition of the visual cue discrimination indicate that rats required approximately 60-70 trials to reach criterion (see Figure 5A). The difference in trials to criterion among the groups was not significant, $F(2$, 17) $=0.18, p>.05$. Thus, inactivation of the dorsal striatum did 

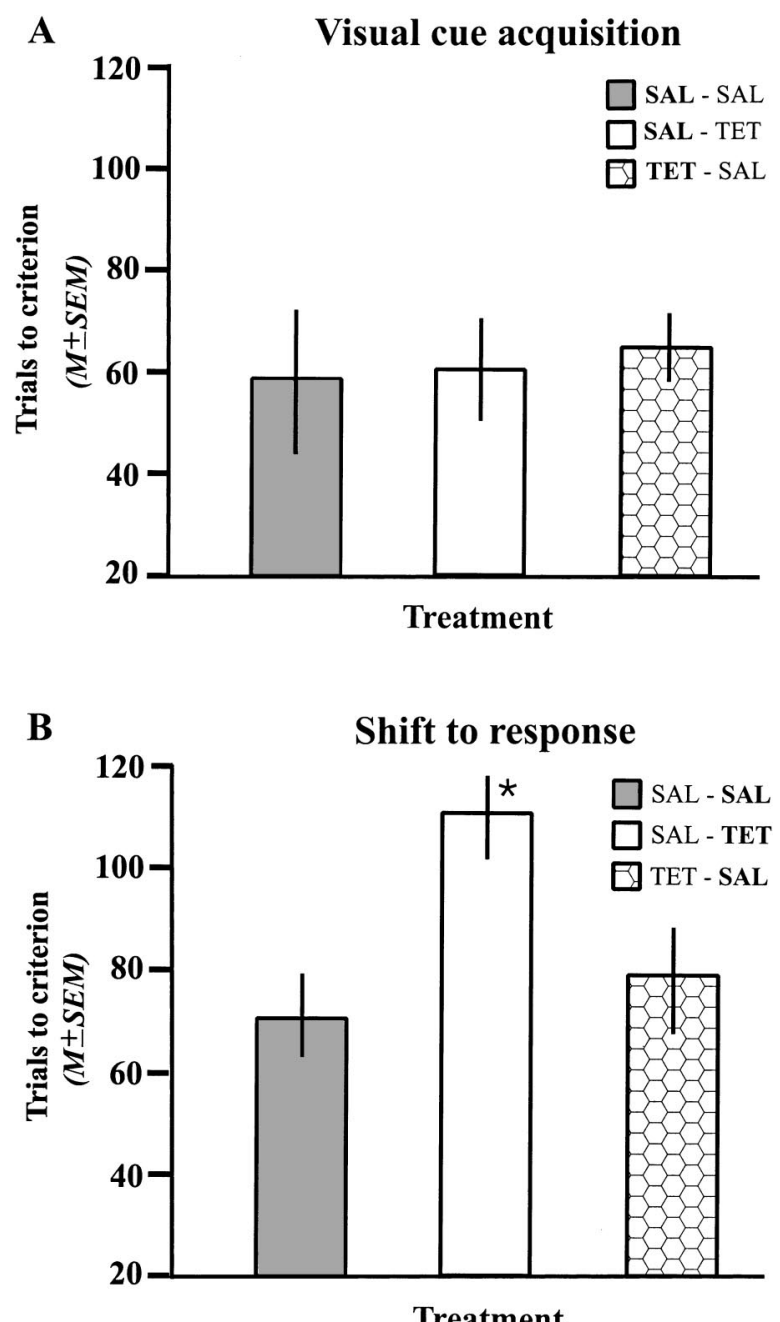

Figure 5. A: Mean $( \pm S E M)$ trials to criterion of acquisition of the visual cue discrimination after bilateral infusions of saline (SAL) or 2\% (wt/vol) tetracaine (TET) into the dorsomedial striatum. TET infusions did not alter acquisition rates compared with SAL infusions. The treatment received on this test is shown in bold for each group. B: Mean ( \pm SEM) trials to criterion on the shift to the response discrimination after SAL or TET infusions into the dorsomedial striatum. TET infusions significantly increased the trials to criterion compared with SAL infusions. The treatment received on this test is shown in bold for each group. Asterisk indicates a significant difference between treatment groups $(p<.05)$.

not impair initial learning of a visual cue discrimination. Furthermore, the difference in the number of probe trials on acquisition was not significant, $F(2,17)=0.73, p>.05$. The mean number ( $\pm S E M$ ) of probe trials to complete acquisition was as follows: saline-saline $=1.33 \pm 0.33$, saline-tetracaine $=1.14 \pm 0.14$, and tetracaine-saline $=1.00 \pm 0.0$.

Shift to response. Tetracaine infusions into the dorsomedial striatum impaired the shift to response discrimination learning (see Figure 5B). The two saline groups reached criterion in approximately $70-80$ trials. In contrast, the tetracaine group was slower in reaching criterion, needing approximately 110 trials to reach criterion. The difference in trials to criterion was significant among the groups, $F(2,17)=4.69, p<.05$. A post hoc analysis with Newman-Keuls tests revealed that the tetracaine-treated group took significantly more trials to reach criterion compared with those of the saline-treated groups $(p s<.05)$. The difference in trials to criterion between the saline groups was not significant $(p>.05)$. The following scores indicate the mean number $( \pm$ $S E M)$ of probe trials to reach criterion for the three groups: saline-saline $=1.17 \pm 0.17$, saline-tetracaine $=1.14 \pm 0.13$, tetracaine-saline $=1.17 \pm 0.15$. The difference in the number of probe trials to reach criterion among the groups was not significant, $F(2,17)=0.008, p>.05$.

A further analysis of the trials to criterion on the shift to response discrimination revealed that dorsal striatum inactivation did not impair learning on the switch due to perseveration (see Figure 6A). The difference in perseverative errors among the groups was not significant, $F(2,17)=0.005, p>.05$. There was a significant difference in regressive errors among the groups, $F(2$, $17)=4.23, p<.05$ (see Figure 6B). Newman-Keuls tests indicated that tetracaine-treated rats made significantly more regressive errors than either of the saline-treated groups ( $p s<.05)$. The difference in regressive errors between the saline-treated groups was not significant $(p>.05)$.

An error could also be made during the switch to the response discrimination on those trials in which the correct egocentric response was the same turn required to enter the visual cue arm. As observed in Experiment 1, the majority of rats never made such an error. For this type of error, the mean scores $( \pm S E M)$ were as follows for the groups: saline-saline $=0.67 \pm 0.46$, salinetetracaine $=0.29 \pm 0.29$, and tetracaine-saline $=0.71 \pm 0.29$. The difference in the errors among the groups was not significant, $F(2,17)=0.53, p>.05$.

\section{General Discussion}

The present results indicate that inactivation of the dorsomedial striatum impairs behavioral flexibility that involves shifts between response and visual cue discriminations. The findings are consistent with a previous experiment that demonstrated electrolytic lesions of the central striatum impair a shift between place and response learning (Thompson, Guilford, \& Hicks, 1980). Inactivation or blockade of dopamine $\mathrm{D}_{1}$ receptors in the prelimbic area, which projects to the dorsomedial striatum, also impairs behavioral flexibility when a shift to using a new type of attribute information is required (Ragozzino et al., 1999a, 1999b; Ragozzino et al., 1999). The anatomical and functional linkage between these regions raises the possibility that these two brain areas, along with the other brain structures in this cortico-basal ganglia-thalamic loop (Groenewegen \& Berendse, 1994), act in conjunction to facilitate behavioral flexibility. More specifically, the medial striatum projects to the medial sector of the pallidum that projects to the medial sector of the mediodorsal thalamus that has connections with the prelimbic and infralimbic areas (Groenewegen \& Berendse, 1994). Future experiments will be important in determining what contributions these other brain areas within the corticobasal ganglia-thalamic loop may make to behavioral flexibility. Furthermore, although the findings from the present experiments suggest that the dorsomedial region of the striatum is important for enabling behavioral flexibility, the prelimbic and infralimbic areas also project to the ventral striatum, in particular the "shell" region 
A

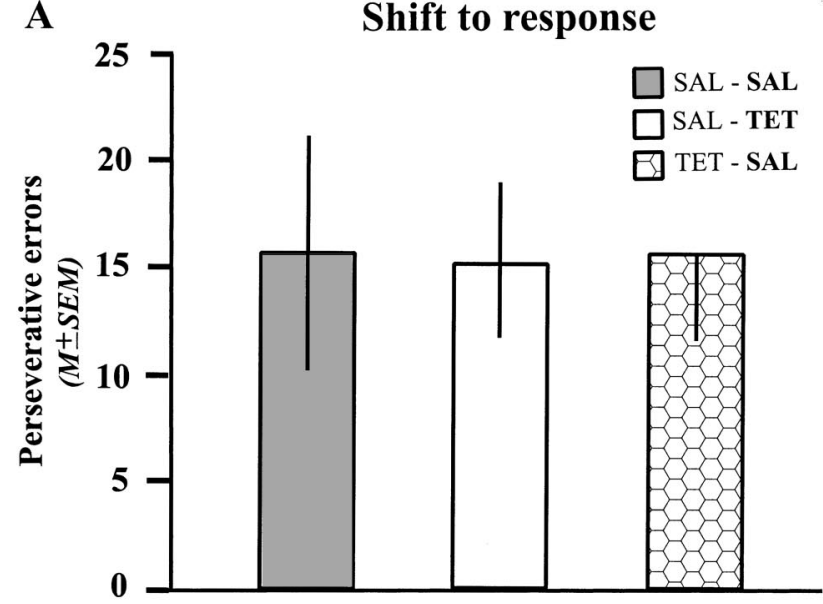

Treatment

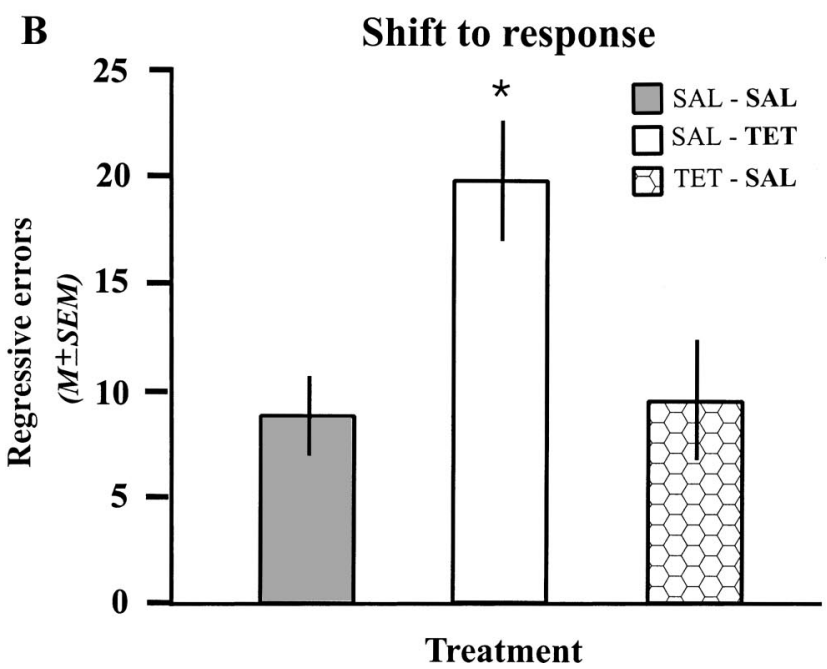

Figure 6. A: Mean $( \pm S E M)$ number of perseverative errors on the shift to the response discrimination after bilateral infusions of saline (SAL) or $2 \%(\mathrm{wt} / \mathrm{vol})$ tetracaine (TET) into the dorsomedial striatum. TET and SAL infusions produced a comparable number of perseverative errors. The treatment received on this test is shown in bold for each group. B: Mean $( \pm$ $S E M$ ) number of regressive errors on the shift to the response discrimination after SAL or TET infusions. TET infusions significantly increased regressive errors compared with SAL infusions. The treatment received on this test is shown in bold for each group. Asterisk indicates a significant difference between treatment groups $(p<.05)$.

of the nucleus accumbens (Groenewegen \& Berendse, 1994). Whether this area may play a similar or distinct role in behavioral flexibility as the dorsomedial striatum or any role in behavioral flexibility is still to be determined.

Although manipulations of the dorsomedial striatum and prelimbic-infralimbic areas both produce behavioral flexibility deficits that require a shift between response and visual cue learning, the pattern of errors that results following inactivation of the dorsomedial striatum and prelimbic-infralimbic areas differs. More specifically, the impairment in extradimensional shifts fol- lowing tetracaine infusions into the prelimbic-infralimbic areas is attributable to perseveration of the previously learned strategy (Ragozzino et al., 1999a). In contrast, the present experiments demonstrated that tetracaine infusions into the dorsomedial striatum impair behavioral flexibility by only increasing regressive errors. In other words, rats with dorsomedial striatal inactivation stop using the previously reinforced response pattern as quickly as control rats, but more often revert back to using the previously correct strategy. These results suggest that the dorsomedial striatum and prelimbic-infralimbic areas may influence distinct processes that enable behavioral flexibility.

In considering the operational definition of perseveration, a criterion of three or four incorrect choices in a block of four was chosen because in this case a predominance of the previously correct choice pattern is still being used during the initial blocks. We considered perseveration to end when a rat was no longer making a predominance of the previously correct choice pattern, but instead was using equally the previously correct choice pattern and the new correct choice pattern in a block or predominantly using the new correct choice pattern. After perseveration ended, a reversion back to the previously relevant choice was referred to as a regressive error. Thus, when perseveration ended a rat was no longer preferentially using the previous strategy, but began to use the new strategy at least as often. On the basis of this criterion, dorsomedial striatal inactivation did not impair the initial shift away from using the previously relevant strategy in either experiment. However, dorsomedial striatal inactivation did increase the number of times a rat reverted back to using the previously relevant strategy as it began learning to use the new, relevant strategy.

The pattern of increased regressive but not perseverative errors observed following dorsomedial striatal inactivation is analogous to findings in Parkinson's disease in which patients exhibit deficits in maintaining, rather than initiating, a new strategy (Downes et al., 1989; Flowers \& Roberston, 1985). Furthermore, in cognitive flexibility tests, medicated Parkinson's disease patients can switch from a previously relevant stimulus dimension but are impaired on switching to a new, previously irrelevant stimulus dimension (Owen et al., 1993). In contrast, frontal lobe damaged patients are impaired on a shift from a previously relevant dimension. A possible explanation for the previous results indicating prelimbicinfralimbic inactivation impairs behavioral flexibility is that the prefrontal cortex is involved in the inhibition of a previously learned strategy, the generation of new strategies, or both (Owen et al., 1993; Wise, Murray, \& Gerfen, 1996). Thus, when the prelimbic-infralimbic regions are inactivated, rats may continue to use the previously reinforced response pattern, either because it is not being suppressed or because new response options have not been generated.

The deficits observed following dorsomedial striatal inactivation and those with Parkinson's disease patients are consonant with the idea proposed by Wise and colleagues (1996) that the striatum facilitates the execution of effective strategies for a particular behavioral context by reinforcing the correct response pattern when generated. However, because inactivation did not prevent the initial shift away from the previously relevant strategy, the dorsomedial striatum may not be critical for the generation of new strategies. If the dorsomedial striatum was crucial for generating a new strategy, then inactivation of this area should have led to the 
inability to abandon the previous response pattern as manifested by a significant increase in perseverative errors; however, this was not observed. Instead, dorsomedial striatal inactivation led to an increased reversion to the previously relevant strategy consistent with the idea that this area facilitates the execution or learning of a new strategy.

Previous results indicate that Parkinson's disease patients are also impaired on cognitive flexibility tasks that involve an intradimensional shift within a visual cue category, as well as an extradimensional shift between a visual cue category (Downes et al., 1989). For example, Parkinson's disease patients are impaired in shifting their response pattern between two different shaped objects as required by an intradimensional shift, as well as impaired in shifting their choice pattern based on shape to one based on color, as required by an extradimensional shift. In a comparable manner, electrical stimulation or lesions of the rat striatum impair different forms of intradimensional shifts, which involve a switch within the same attribute category (Hannon \& Bader, 1974; Kirkby, 1969; Kolb, 1977, Livesey \& Muter, 1976; Pisa \& Cyr, 1990). In contrast, inactivation of the rat prelimbic-infralimbic areas or prefrontal lesions in humans impair switching between different attributes but not within the same attribute (Owen, Roberts, Polkey, Sahakian, \& Robbins, 1991; Owen et al., 1993; Ragozzino et al., 1999a, 1999b). Taken together, the findings indicate, relative to the prefrontal cortex, the striatum may facilitate the execution of a wider range of situationally adaptive responses.

The present experiments demonstrated that dorsomedial striatal inactivation selectively impaired learning when rats had to shift between a response and visual cue discrimination, but did not impair the initial learning of a response or visual cue discrimination. These results suggest that the deficit on the reversal learning phase was not due to general impairments in learning, nor any motivational or motor side effects. These findings are consistent with some previous studies indicating that dorsomedial striatal lesions do not impair acquisition of discrimination tasks (Kolb, 1977; Pisa \& Cyr, 1990; Thompson et al., 1980). The purpose of the present experiments was to inactivate the dorsomedial striatal region because this area receives projections from the prelimbic and infralimbic areas, which we found to be important in behavioral flexibility (Ragozzino et al., 1999a, 1999b; Ragozzino et al., 1999). One possibility is that inactivating a larger area may have impaired initial acquisition. In a testing procedure comparable to the one used in the present experiments, neurotoxic lesions encompassing a larger area of the medial striatum did not impair acquisition of a response or visual cue discrimination, suggesting that even damage to a larger region of the medial striatum does not impair acquisition (Pisa \& Cyr, 1990). Furthermore, the findings from another experiment suggest that the lateral striatum may be critical in learning a discrimination for visual cue and possibly response information (McDonald \& White, 1994).

Other investigations have reported a deficit on acquisition of discrimination tasks following dorsomedial striatal lesions (Brown \& Robbins, 1989; Devan et al., 1999; Devan \& White, 1999; Whishaw et al., 1987). However, in most of these studies, the learning impairments were observed on acquisition of the place and visual cue versions of the water maze task. In these experiments, dorsomedial striatal lesions increased thigmotaxis during initial trials for both the visual cue and place discriminations but did not prevent the learning of the discriminations (Devan et al., 1999; Devan \& White, 1999). This has led White and colleagues (Devan et al., 1999; Devan \& White, 1999) to suggest that the dorsomedial striatum is important in the selection of alternative response patterns, which is consistent with the present findings in which dorsomedial striatal inactivation impaired the ability to reliably execute an alternative response pattern during the shift to a different discrimination.

It may also be possible to reconcile the present findings suggesting that the dorsomedial striatum enhances behavioral flexibility with earlier theories of the striatum as a mediator of habit learning (Graybiel, 1998; Mishkin et al., 1984; Packard et al., 1989). In the case of discrimination learning, behavioral flexibility is distinct from habit learning in that one response pattern that was previously relevant must be inhibited while a new response pattern must be learned when environmental demands are switched. However, after the initial shift away from the previously relevant response pattern in behavioral flexibility tests, the accurate use of a specific response pattern must be used as in habit learning. The observed regressive errors in these experiments could be viewed as an impaired ability to "automate" a newly reinforced response pattern. However, traditional habit learning theories have limited the role of the striatum to learning in which conditions demand a simple response pattern that must be repeated across trials and do not require flexible responding. The present data clearly indicate this view of the striatum needs to be expanded, or at least considered, to the dorsomedial striatum playing a critical role in enabling the execution of effective response patterns when conditions change. In fact, the changing of behavioral demands may be a primary factor triggering dorsomedial striatal activation.

\section{References}

Adams S., Kesner R. P., \& Ragozzino M. E. (2001). Role of the medial and lateral caudate-putamen in mediating an auditory conditional response association. Neurobiology of Learning and Memory, 76, 106-116.

Aosaki T., Kimura M., \& Graybiel A. M. (1995). Temporal and spatial characteristics of tonically active neurons of the primate's striatum. Journal of Neurophysiology, 73, 1234-1252.

Beninger R. J., \& Ranaldi R. (1993). Microinjections of flupenthixol into the caudate-putamen but not the nucleus accumbens, amygdala or frontal cortex of rats produce intra-session declines in food-rewarded operant responding. Behavioural Brain Research, 55, 203-212.

Brown, V. J., \& Robbins, T. W. (1989). Elementary processes of response selection mediated by distinct regions of the striatum. Journal of Neuroscience, 9, 3760-3765.

Colombo P. J., Davis H. P., \& Volpe B. T. (1989). Allocentric spatial and tactile memory impairments in rats with dorsal caudate lesions are affected by preoperative behavioral training. Behavioral Neuroscience, $103,1242-1250$.

Cook D., \& Kesner R. P. (1988). Caudate nucleus and memory for egocentric localization. Behavioral and Neural Biology, 49, 332-343.

Devan B. D., McDonald R. J., \& White N. M. (1999). Effects of medial and lateral caudate-putamen lesions on place- and cue-guided behaviors in the water maze: Relation to thigmotaxis. Behavioural Brain Research, 100, 5-14.

Devan B. D., \& White N. M. (1999). Parallel information processing in the dorsal striatum: Relation to hippocampal function. Journal of Neuroscience, 19, 2789-2798.

Divac, I. (1971). Frontal lobe system and spatial reversal in the rat. Neuropsychologia, 9, 175-183. 
Downes J. J., Roberts A. C., Sahakian B. J., Evenden J. L., Morris R. G., \& Robbins T. W. (1989). Impaired extra-dimensional shift performance in medicated and unmedicated Parkinson's disease: Evidence for a specific attentional dysfunction. Neuropsychologia, 27, 1329-1343.

Duncan-Davis, J., Filoteo, J. V., \& Kesner, R. P. (1996, April). Memory impairment for spatial locations and motor movements in patients with Huntington's disease. Paper presented at the annual meeting of the Cognitive Neuroscience Society, San Francisco.

Dunnett S. B., \& Iversen S. D. (1982). Sensorimotor impairments following localized kainic acid and 6-hydroxydopamine lesions of the neostriatum. Brain Research, 248, 121-127.

Flowers K. A., \& Robertson (1985). The effect of Parkinson's disease on the ability to maintain a mental set. Journal of Neurology, Neurosurgery and Psychiatry, 48, 517-529.

Fricker R. A., Annett L. E., Torres E. M., \& Dunnett S. B. (1996). The placement of a striatal ibotenic acid lesion affects skilled forelimb use and direction of drug-induced rotation. Brain Research Bulletin, 41, 409-416.

Ghiselli E. E., \& Brown C. W. (1938). Subcortical mechanisms in learning V. Inclined plane discrimination. Journal of Comparative Psychology, 22, 271-285.

Graybiel, A. M. (1998). The basal ganglia and chunking of action repertoires. Neurobiology of Learning and Memory, 70, 119-136.

Groenewegen, H. J., \& Berendse, H. W. (1994). Anatomical relationships between the prefrontal cortex and basal ganglia in the rat. In A. M. Thierry, J. Glowinski, P. S. Goldman-Rakic, \& Y. Christen (Eds.), Motor and cognitive functions of the prefrontal cortex (pp. 51-77). Berlin: Springer-Verlag.

Hannon, R., \& Bader, A. (1974). A comparison of frontal pole, anterior median and caudate nucleus lesions in the rat. Physiology \& Behavior, 13, 513-521.

Haralambous, T., \& Westbrook, R. F. (1999). An infusion of bupivacaine into the nucleus accumbens disrupts the acquisition but not the expression of contextual fear conditioning. Behavioral Neuroscience, 113, 925-940.

Hunt, P. R., \& Aggleton, J. P. (1998). Neurotoxic lesions of the dorsomedial thalamus impair the acquisition but not the performance of delayed match to place by rats: A deficit in shifting response rules. Journal of Neuroscience, 18, 10045-10052.

Kesner, R. P. (1998). Neurobiological views of memory. In J. Martinez \& R. Kesner (Eds.), Neurobiology of learning and memory (pp. 361-405). New York: Academic Press.

Kesner, R. P., Bolland, B. L., \& Dakis, M. (1993). Memory for spatial locations, motor responses, and objects: Triple dissociation among the hippocampus, caudate nucleus, and extrastriate visual cortex. Experimental Brain Research, 93, 462-470.

Kirkby, R. J. (1969). Caudate nucleus lesions and perseverative behavior. Physiology \& Behavior, 4, 451-454.

Knowlton, B. J., Mangels, J. A., \& Squire L. R. (1996, September 6). A neostriatal habit learning system in humans. Science, 273, 1399-1402.

Kolb, B. (1977). Studies on the caudate-putamen and the dorsomedial thalamic nucleus of the rat: Implications for mammalian frontal-lobe functions. Physiology \& Behavior, 18, 237-244.

Lawrence, A. D., Sahakian, B. J., Hodges, J. R., Rosser, A. E., Lange, K. W., \& Robbins, T. W. (1996). Executive and mnemonic functions in early Huntington's disease. Brain, 119, 1633-1645.

Livesey, P. J., \& Muter, V. (1976). Functional differentiation within the neostriatum of the rat using electrical (blocking) stimulation during discrimination learning. Journal of Comparative and Physiological Psychology, 90, 203-211.

McDonald, R. J., \& White, N. M. (1993). A triple dissociation of memory systems: Hippocampus, amygdala and dorsal striatum. Behavioral Neuroscience, 107, 3-22.

McDonald, R. J., \& White, N. M. (1994). Parallel information processing in the water maze: Evidence for independent memory systems involving dorsal striatum and hippocampus. Behavioral and Neural Biology, 61, 260-270.

McGeorge, A. J., \& Faull, R. L. M. (1989). The organization of the projection from the cerebral cortex to the striatum in the rat. Neuroscience, 29, 503-537.

Mishkin, M., Malamut, B., \& Bachevalier, J. (1984). Memories and habits: Two neural systems. In G. Lynch, J. L. McGaugh, \& N. M. Weinberger (Eds.), Neurobiology of human memory and learning (pp. 65-77). New York: Guilford.

Mizumori, S. J. Y., McNaughton, B. L., Barnes, C. A., \& Fox, K. B. (1989). Preserved spatial coding in hippocampal CA1 pyramidal cells during reversible suppression of CA3 output: Evidence for pattern completion in hippocampus. Journal of Neuroscience, 9, 3915-3928.

Mizumori, S. J. Y., Perez, G. M., Alvarado, M. C., Barnes, C. A., \& McNaughton, B. L. (1990). Reversible inactivation of the medial septum differentially affects two forms of learning in rats. Brain Research, 328, $12-20$.

Mizumori, S. J. Y., Ragozzino, K. E., \& Cooper, B. G. (2000). Location and head direction representation in the dorsal striatum of rats. Psychobiology, 28, 441-462.

Owen, A. M., Roberts, A. C., Hodges, J. R., Summers, B. A., Polkey, C. E., \& Robbins, T. W. (1993). Contrasting mechanisms of impaired attentional set-shifting in patients with frontal lobe damage or Parkinson's disease. Brain, 116, 1159-1176.

Owen, A. M., Roberts, A. C., Polkey, C. E., Sahakian, B. J., \& Robbins, T. W. (1991). Extra-dimensional versus intra-dimensional set shifting performance following frontal lobe excisions, temporal lobe excisions or amygdalo-hippocampectomy in man. Neuropsychologia, 29, 993-1006.

Packard, M. G. (1999). Glutamate infused post-training into the hippocampus or caudate-putamen differentially strengthens place and response learning. Proceedings of the National Academy of Sciences, USA, 96, 12881-12886.

Packard, M. G., Hirsh, R., \& White, N. M. (1989). Differential effects of fornix and caudate nucleus lesions on two radial maze tasks: Evidence for multiple memory systems. Journal of Neuroscience, 9, 1465-1472.

Packard, M. G., \& McGaugh, J. L. (1996). Inactivation of the hippocampus or caudate nucleus with lidocaine differentially affects expression of place and response learning. Neurobiology of Learning and Memory, 65, $66-72$.

Packard, M. G., \& Teather, L. A. (1997). Double dissociation of hippocampal and dorsal-striatal memory systems by post-training intracerebral injections of 2-amino-5-phosphonopentanoic acid. Behavioral Neuroscience, 111, 543-551.

Packard, M. G., \& White, N. M. (1991). Dissociation of hippocampus and caudate nucleus memory systems by posttraining intracerebral injection of dopamine agonists. Behavioral Neuroscience, 105, 295-306.

Paxinos, G., \& Watson, C. (1996). The rat brain in stereotaxic coordinates (3rd ed.). Sydney, Australia: Academic Press.

Pisa, M., \& Cyr, J. (1990). Regionally selective roles of the rat's striatum in modality specific discrimination learning and forelimb reaching. Behavioural Brain Research, 37, 281-292.

Potegal, M. (1969). Role of the caudate nucleus in spatial orientation of rats. Journal of Comparative and Physiological Psychology, 69, 756764.

Ragozzino, M. E., Detrick, S., \& Kesner, R. P. (1999a). Involvement of the prelimbic-infralimbic areas of the rodent prefrontal cortex in behavioral flexibility for place and response learning. Journal of Neuroscience, 19 , $4585-4594$.

Ragozzino, M. E., Detrick, S., \& Kesner, R. P. (1999b). The role of prelimbic-infralimbic dopamine D, receptors in behavioral flexibility. Society for Neuroscience Abstracts, 25, 890.

Ragozzino, M. E., \& Kesner, R. P. (1998). The effects of muscarinic cholinergic receptor blockade in the rat anterior cingulate and prelimbic/ 
infralimbic cortices on spatial working memory. Neurobiology of Learning and Memory, 69, 233-243.

Ragozzino, M. E., Wilcox, C., Raso, M., \& Kesner R. P. (1999). Involvement of rodent prefrontal cortex subregions in strategy switching. Behavioral Neuroscience, 113, 32-41.

Reading, P. J., Dunnett, S. B., \& Robbins T. W. (1991). Dissociable roles of the ventral, medial and lateral striatum on the acquisition and performance of a complex visual stimulus response habit. Behavioural Brain Research, 45, 147-161.

Schwartzbaum, J. S., \& Donovick, P. J. (1968). Discrimination reversal and spatial alternation associated with septal and caudate dysfunction in rats. Journal of Comparative and Physiological Psychology, 65, 83-92.

Thompson, W. G., Guilford, M. O., \& Hicks, L. H. (1980). Effects of caudate and cortical lesions on place and response learning in rats. Physiological Psychology, 8, 473-479.

Thomsen, W., Hays, S. J., Hicks, L. J., Schwarz, R. D., \& Catteral, W. A. (1993). Specific binding of the novel NA+ channel blocker PD85,639 to the alpha subunit of rat brain NA+ channels. Molecular Pharmacology, 43, 955-964.

Uylings, H. B. M., \& van Eden, C. G. (1990). Qualitative and quantitative comparison of the prefrontal cortex in rat and in primates including humans. Progress in Brain Research, 85, 31-62.

Velly, J., Grima, M., Decker, N., Cragoe, E. J., \& Schwartz, J. (1988). Effects of amiloride and its analogues on 3-H-batrachotoxinin-A-20- alpha benzoate binding, 3-H tetracaine binding, and 22NA influx. European Journal of Pharmacology, 149, 97-105.

Whishaw, I. Q., Mittleman, G., Bunch, S. T., Dunnett, S. B. (1987). Impairments in the acquisition, retention and selection of spatial navigation strategies after medial caudate-putamen lesions in rats. Behavioural Brain Research, 24, 125-138.

White, N. M., \& Viaud, M. (1991). Localized intracaudate dopamine D2 receptor activation during post-training period improves memory for visual or olfactory conditioned emotional responses in rats. Behavioral and Neural Biology, 55, 255-269.

Winocur, G. (1974). Functional dissociation within the caudate nucleus of rats. Journal of Comparative and Physiological Psychology, 86, 432439.

Winocur, G., \& Eskes, G. (1998). Prefrontal cortex and caudate nucleus in conditional associative learning: Dissociated effects of selective brain lesions in rats. Behavioral Neuroscience, 112, 89-101.

Wise, S. P., Murray, E. A., \& Gerfen, C. R. (1996). The frontal cortexbasal ganglia system in primates. Critical Reviews in Neurobiology, 10, 317-356.

Received April 11, 2001

Revision received August 6, 2001

Accepted August 21, 2001

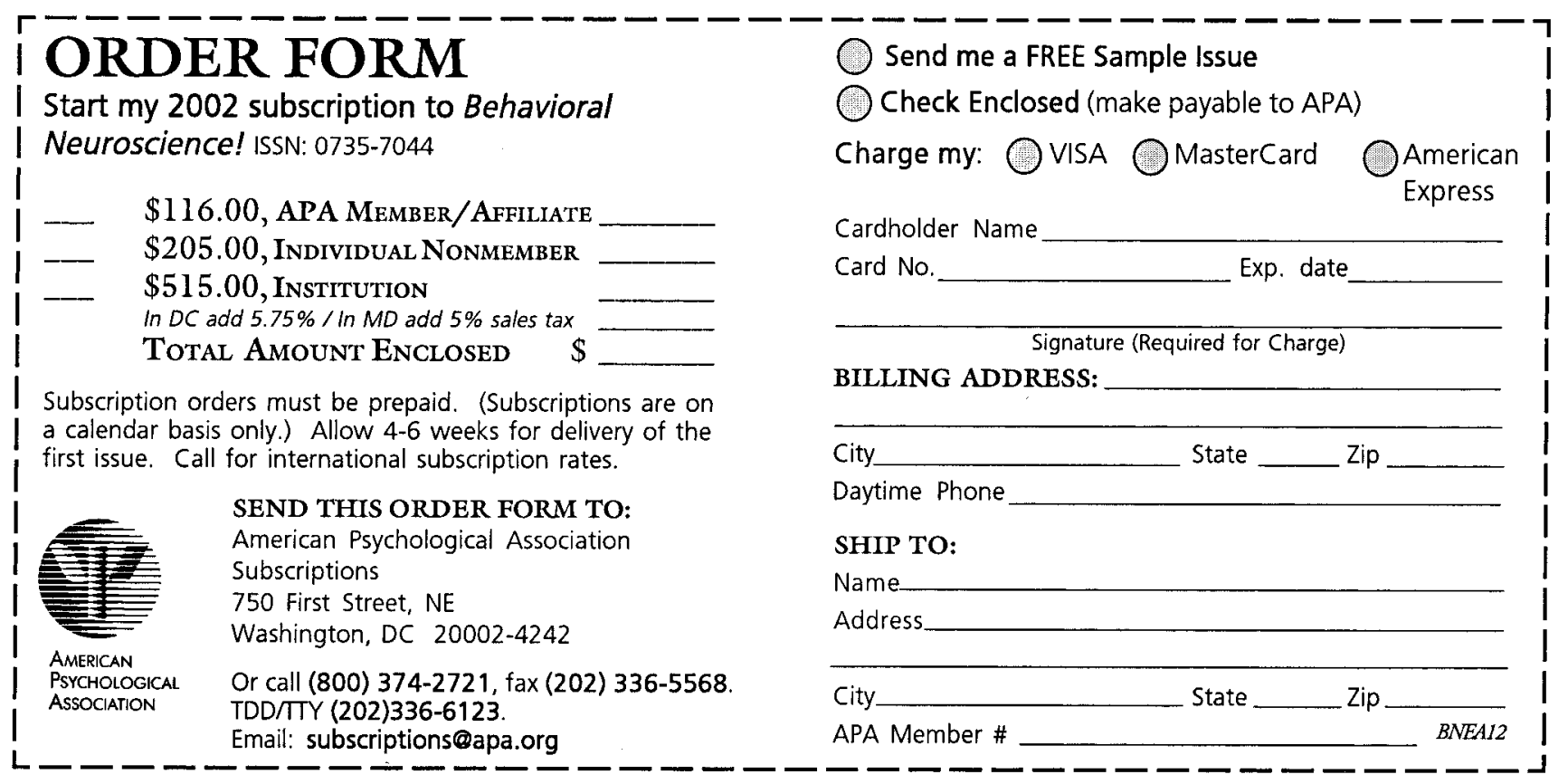

